\title{
THE IN VITRO EFFECTS OF DEXAMETHASONE, INSULIN AND TRIIODOTHYRONINE ON DEGENERATIVE HUMAN INTERVERTEBRAL DISC CELLS UNDER NORMOXIC AND HYPOXIC CONDITIONS
}

Alessandro Bertolo ${ }^{1,2}$, Ladina Ettinger ${ }^{1}$, Niklaus Aebli ${ }^{6,3}$, Daniel Haschtmann ${ }^{1}$, Martin Baur ${ }^{4}$, Ulrich Berlemann ${ }^{5}$ Stephen J. Ferguson ${ }^{1}$ and Jivko V. Stoyanov ${ }^{1,2}$

\author{
${ }^{1}$ Institute for Surgical Technology and Biomechanic, University of Bern, Bern, Switzerland \\ ${ }^{2}$ Biomedical Laboratories, Swiss Paraplegic Research, Nottwil, Switzerland \\ ${ }^{3}$ School of Medicine, Griffith University, Brisbane, Queensland, Australia \\ ${ }^{4}$ Cantonal Hospital of Lucern, Luzern, Switzerland \\ ${ }^{5}$ Das Rückenzentrum, Thun, Switzerland \\ ${ }^{6}$ Swiss Paraplegic Center, Nottwil, Switzerland
}

\begin{abstract}
Degeneration of intervertebral discs (IVD) is one of the main causes of back pain and tissue engineering has been proposed as a treatment. Tissue engineering requires the use of highly expensive growth factors, which might, in addition, lack regulatory approval for human use. In an effort to find readily available differentiation factors, we tested three molecules - dexamethasone, triiodothyronine (T3) and insulin - on human IVD cells isolated after surgery, expanded in vitro and transferred into alginate beads. Triplicates containing $40 \mathrm{ng} / \mathrm{ml}$ dexamethasone, $10 \mathrm{nM} \mathrm{T3}$ and $10 \mu \mathrm{g} / \mathrm{ml}$ insulin, together with a positive control (10 $\mathrm{ng} / \mathrm{mL}$ transforming growth factor (TGF)- $\beta 1$ ), were sampled weekly over six weeks and compared to a negative control. Furthermore, we compared the results to cultures with optimized chondrogenic media and under hypoxic condition $\left(2 \% \mathrm{O}_{2}\right)$. Glycosaminoglycan (GAG) determination by alcian blue assay and histological staining showed dexamethasone to be more effective than T3 and insulin, but less than TGF- $\beta 1$. DNA quantification showed that only dexamethasone stimulated cell proliferation. qPCR demonstrated that TGF- $\beta 1$ and the optimized chondrogenic groups increased the expression of collagen type II, while aggrecan was stimulated in cultures containing dexamethasone. Hypoxia increased GAG accumulation, collagen type II and aggrecan expression, but had no effect on or even lowered cell number. In conclusion, dexamethasone is a valuable and cost-effective molecule for chondrogenic and viability induction of IVD cells under normoxic and hypoxic conditions, while insulin and T3 did not show significant differences.
\end{abstract}

Keywords: Intervertebral disc degeneration, dexamethasone, insulin, triiodothyronine, cartilage, collagen, aggrecan, glycosaminoglycan.

*Address for correspondence:

Jivko V. Stoyanov

Biomedical Laboratories

Swiss Paraplegic Research

G.A.Zaech Strasse 4, CH 6207 Nottwil

Switzerland

Telephone Number: +41419396635

FAX Number: +41419396640

E-mail: jivko.stoyanov@paranet.ch
Introduction

Intervertebral disc (IVD) degeneration is a multi-factorial, age-dependent process. Clinically, the degenerative process can be asymptomatic, but it also may lead to acute or chronic back pain which often ultimately is treated surgically, with varying results in terms of effectiveness and patient satisfaction (Borenstein et al., 2001; Lee and Langrana, 2004; Adams et al., 2006). While the etiology of disc degeneration is heterogeneous, the quality of the surgically extracted degenerated tissues is mostly poor, showing disturbance in the morphological organization and impaired mechano-biological properties of the tissue due to proteolytic activity and decreased proteoglycan content (Antoniou et al., 1996). Using disc cells extracted from such degenerated tissues represents a substantial challenge for the biological regeneration of the disc. For this reason, stimulation and activation of IVD cells in culture will be a necessity for future autologous and allogenic cell-based therapies.

Stimulation of IVD cells in vitro and in vivo have been the focus of a number of articles that deal with the topic of restoring the biological function of degenerated IVD cells. In vivo therapeutic approaches were based on the use of various natural or recombinant proteins, either administered directly or via gene therapy (Chadderdon et al., 2004), or in vitro by direct supplementation to cell culture of these factors (Gruber et al., 2001). Some of the most utilized factors, with proven effects, are transforming growth factor beta (TGF- $\beta$ ), insulin-like growth factor I (IGF-I) (Walsh et al., 2004) and bone morphogenic proteins (BMP) (Fei et al., 2006). Other, such as fibroblast growth factor-2 (FGF-2) (Tsai et al., 2007) and growth differentiation factor-5 (GDF-5) (Chujo et al., 2006), have also been shown to be promising -although not so widely employed in the IVD. The study of the effects of such growth factors requires not only substantial evaluation in the laboratory, but translation of their use for the purpose of regenerative medicine will require regulatory permission for their clinical use, which is another huge investment. The legal limitations and high costs of the growth factors can be even now be a bottleneck stage for laboratories that investigate the potential of regenerative disc repair in humans. They will certainly become a huge burden for national health care systems once the stage of medical innovation translates into routine clinical applications. Therefore, it would be beneficial to find readily available substitutes for these growth factors, 
namely molecules, which will allow cells for autologous and allogenic transplantation to be optimized, for their extracellular matrix production, with the potential to be used later in clinical practice without regulatory problems.

Thus, we tested bioactive, readily available molecules that had modes of action in two directions: (1) to protect against cell death - i.e., to preserve or increase the number of cells in a given sample (considering the limited number of viable donor cells); (2) to use the differentiation potential of the - thus-expanded - disc cells in order to attain the physiological, functional and biological properties of disc tissue (e.g., preserve and stimulate the ability of cells to produce and accumulate extracellular matrix).

Here we tested the ability of three molecules dexamethasone, insulin and triiodothyronine - to stimulate cell proliferation and proteoglycan synthesis in degenerated disc cells embedded in three-dimensional cultures, under normoxic and hypoxic conditions. Our selection criteria were based on the molecules' bioactive in vitro and in vivo properties, affordability and approval for clinical use. Dexamethasone, a synthetic glucocorticoid, is widely used in the medical practice for its anti-inflammatory properties. It has been demonstrated to stimulate chondrogenesis in chondrocytes (Grigoriadis et al., 1989; Quarto et al., 1992; Quarto et al., 1997; Na et $a l ., 2006)$ and, together with TGF- $\beta$, in mesenchymal stem cells (MSCs) (Johnstone et al., 1998; Derfoul et al., 2006). Insulin's multiple functions in the organism include stimulation of the glucose uptake and the catabolism of carbohydrates, but it also promotes protein biosynthesis and chondrocyte proliferation (Quarto et al., 1992; Dever, 2002, Phornphutkul et al., 2006). Triiodothyronine (T3), an iodine-containing hormone secreted by the thyroid gland, regulates development, stimulates oxidative metabolism (Hanken et al., 1988) and has been shown to play a role in the differentiation of chondrocytes (Quarto et al., 1992; Kawaguchi et al., 2005).

In the present study, using TGF- $\beta 1$ as a positive control, we assessed the three molecules for their mitogenic potential upon cells - by measuring total DNA concentration and their differentiation abilities, by means of a proteoglycan accumulation assay, histological and immunohistochemical analysis and determining the upregulation of the transcription of the extracellular matrix genes, collagen type II and aggrecan.

\section{Materials and Methods}

\section{Isolation and culture of human disc cells}

Disc cells were isolated from human disc tissue $(n=5)$, obtained after full or partial discectomy (Table 1) and approval by a local ethics committee. Disc fragments were sequentially digested with: (1) $0.3 \%$ pronase (SigmaAldrich, St. Louis, MO, USA), $10 \%$ fetal bovine serum (FBS), penicillin (100 units/mL) \& streptomycin (100 mg/ $\mathrm{mL}$ ) in DMEM/F12 + GlutaMAX (all GIBCO) for $1 \mathrm{~h}$ at $37^{\circ} \mathrm{C}$; (2) $0.05 \%$ collagenase (Sigma-Aldrich), $10 \% \mathrm{FBS}$, penicillin (100 units $/ \mathrm{mL}) \&$ streptomycin $(100 \mathrm{mg} / \mathrm{mL})$ in DMEM/F12 + GlutaMAX for $14 \mathrm{~h}$ at $37^{\circ} \mathrm{C}$. The cell populations for two donors were mixed, because annulus fibrous (AF) and nucleus pulposus (NP) could not be distinguished at this stage of degeneration, during the surgical procedure.

Disc cells were expanded in culture for 20 days (two passages) - as a monolayer in DMEM/F12 + GlutaMAX, supplemented with $10 \% \mathrm{FBS}$, penicillin (100 units/mL) \& streptomycin (100 mg/mL), $2.5 \mathrm{ng} / \mathrm{ml} \mathrm{Amphotericin} \mathrm{B}$ (Gibco, Paisley, UK) and $5 \mathrm{ng} / \mathrm{ml}$ recombinant bFGF (Peprotech, Rocky Hill, NJ, USA) at $37^{\circ} \mathrm{C}$ in a humid atmosphere containing $5 \% \mathrm{CO}_{2}$, with media changed 3 times a week. Cells were then encapsulated in threedimensional $1.2 \%$ alginate bead culture at 4,000,000 cells/ $\mathrm{mL}$ density (each bead having approximately 80,000 cells). Alginate (Fluka/Sigma-Aldrich) was selected as a suitable matrix material because of comparable performance to agarose (Almqvist et al., 2000; Diduch et al., 2000), while avoiding the heat shock associated with agarose beads. Beads, loaded with cells, were cultured for up to 6 weeks in the presence of $40 \mathrm{ng} / \mathrm{ml}$ dexamethasone, $10 \mathrm{nM}$ triiodothyronine or $10 \mu \mathrm{g} / \mathrm{ml}$ insulin (all Sigma-Aldrich) - added to the basal medium (10\% FBS, $50 \mu \mathrm{g} / \mathrm{ml}$ ascorbate (AppliChem, Darmstadt, Germany), penicillin (100 units/ $\mathrm{mL})$ \& streptomycin $(100 \mathrm{mg} / \mathrm{mL})$ and $2.5 \mathrm{ng} / \mathrm{ml}$ Amphotericin B). Parallel cultures were also run as negative (just basal medium) and positive control (basal medium + 10 ng/mL TGF- $\beta 1$ (Peprotech)). Beads were sampled in triplicate on a weekly basis.

As a further control, disc cells were cultured in an optimized chondrogenic medium (10\% FBS, $10 \mathrm{ng} / \mathrm{mL}$ TGF- $\beta 1,50 \mu \mathrm{g} / \mathrm{ml}$ L-proline (AppliChem), $1 \mathrm{X}$ Insulin (10 $\mu \mathrm{g} / \mathrm{ml})$, Transferrin $(5.5 \mu \mathrm{g} / \mathrm{ml})$, Selenium $(0.67 \mathrm{ng} / \mathrm{ml})$, X Supplement (ITS, Gibco), $40 \mathrm{ng} / \mathrm{ml}$ dexamethasone, 50 $\mu \mathrm{g} / \mathrm{ml}$ ascorbate, penicillin (100 units/mL) \& streptomycin (100 mg/mL), $2.5 \mathrm{ng} / \mathrm{ml}$ Amphotericin B) and its negative control (10\% FBS, 1X ITS, $50 \mu \mathrm{g} / \mathrm{ml}$ ascorbate, penicillin (100 units $/ \mathrm{mL}) \&$ streptomycin $(100 \mathrm{mg} / \mathrm{mL}), 2.5 \mathrm{ng} / \mathrm{ml}$ Amphotericin B).

\section{Hypoxic cultures of beads}

Separately, alginate beads were cultured in media containing dexamethasone, triiodothyronine, insulin or TGF- $\beta 1$ for 42 days, under hypoxic conditions. Hypoxia was achieved, using a reduced oxygen concentration $(2 \%$ $\mathrm{O}_{2}$ at $37^{\circ} \mathrm{C}$ in humidified atmosphere, Life Imaging Service, hypoxia chamber, \# 922177, Basel, Switzerland).

\section{Glycosaminoglycan (GAG) accumulation and DNA assays.}

Proteoglycan accumulation was quantified using an alcian blue binding assay, after overnight digestion of three alginate beads per sample at $60^{\circ} \mathrm{C}$ with $125 \mu \mathrm{g} / \mathrm{ml}$ papain (Sigma-Aldrich) in $5 \mathrm{mM}$ L-cysteine-HCl (SigmaAldrich), $5 \mathrm{mM} \mathrm{Na-citrate,} 150 \mathrm{mM} \mathrm{NaCl}, 5 \mathrm{mM}$ EDTA (all AppliChem). GAG accumulation was determined by its binding to alcian blue (Fluka): absorption was measured at $595 \mathrm{~nm}$ and quantified against chondroitin sulfate (Sigma-Aldrich) reference standards (Bjornsson et al., 1993).

Total double stranded DNA was measured for each sample, after papain digestion - as previously described. The amount of DNA was determined using SYBR green (Invitrogen) fluorescent assay (absorption measured at 535 
Table 1. Demographic details of donors (Average age $=48$ )

\begin{tabular}{cccccr}
\hline Sample & Sex & $\begin{array}{c}\text { Donor's age } \\
\text { (Years) }\end{array}$ & $\begin{array}{c}\text { Type of } \\
\text { Sample }\end{array}$ & $\begin{array}{c}\text { Thompson } \\
\text { Grading Scale }\end{array}$ \\
\hline 1 & F & 44 & NP & IV \\
2 & F & 47 & AF & II & 7 \\
3 & F & 47 & NP & II & 7 \\
4 & M & 50 & MD & III & II \\
5 & M & 52 & MD & .
\end{tabular}

$\mathrm{AF}=$ Annulus Fibrosis; NP = Nucleus Pulposus; $\mathrm{MD}=$ Mixed Disc $;$ DDD = Degenerated Disc Disease

Table 2. Human marker genes used in quantitative RT-PCR. ( $\mathrm{F}=$ Forward, $\mathrm{R}=$ Reverse).

\begin{tabular}{ll}
\hline Gene & Primer nucleotide sequence (5' to 3') \\
\hline GAPDH & F - TGGACTCCACGACGTACTCA \\
& R - GGAAGCTTGTCATCAATGGAA \\
Aggrecan & F - AGGCTATGAGCAGTGTGAACG \\
& R - GCACGCCATAGGTCCTGA \\
Collagen Type II & F - GAAGTGCTGGTGCTCGTG \\
& R - GGCCTCTCCTTGCTCACC \\
\hline
\end{tabular}

$\mathrm{nm}$ ), quantified by referring to calf thymus DNA (SigmaAldrich) standards. All test groups were analyzed in triplicate.

\section{RNA isolation and quantitative PCR}

RNA isolation from the alginate beads was performed at day $7,14,28$ and 42 and then stored at $-80^{\circ} \mathrm{C}$. RNA was isolated using Aurum Total Mini Kit (Bio-Rad, Hercules, CA, USA), adding $2 \mu \mathrm{l}$ polyacryl carrier and following the manufacturer's instructions. $500 \mathrm{ng}$ of total RNA were used for synthesis of cDNA (iScript cDNA Synthesis Kit, Bio-Rad). cDNA was diluted 1:10 with PCR grade water and the resulting complementary DNA template $(5 \mu \mathrm{l})$ was mixed with the PCR reaction solution (IQ SYBR Green Supermix, Bio-Rad) containing $0.25 \mu \mathrm{M}$ specific primers - as described in table 2. Specific products (GAPDH, aggrecan and collagen type II) were amplified by a quantitative PCR system (CFX96 ${ }^{\mathrm{TM}}$ Real Time System, Bio-Rad). Real time PCR was carried out with the following settings: denaturation $95^{\circ} \mathrm{C}$ for $3 \mathrm{~min}$ ( 1 cycle), $95^{\circ} \mathrm{C}$ for $15 \mathrm{~s}, 64^{\circ} \mathrm{C}$ for $20 \mathrm{~s}$ and $72^{\circ} \mathrm{C}$ for $20 \mathrm{~s}(40$ amplification cycles), followed by a melting curve analysis. PCR reactions were carried out in triplicate in a final volume of $25 \mu \mathrm{l}$ in 96-well plates (Bio-Rad). The results were normalized to the expression of GAPDH.

\section{Immunohistochemistry and histological analysis}

Beads were harvested after 42 days of culture in all the media, in normoxic and hypoxic cultures, embedded in OCT Tissue Tek compound for $30 \mathrm{~min}$ and then frozen at $-80^{\circ} \mathrm{C}$. Constructs were subsequently cryo sectioned at 30 $\mu \mathrm{m}$ thickness using a cryostat (CM 1850, Leica, Wetzlar, Germany).

Immunohistochemical analysis was used to detect collagen type II accumulation. Endogenous peroxidases were quenched by $3 \% \mathrm{H}_{2} \mathrm{O}_{2}$ in $0.1 \mathrm{mM} \mathrm{CaCl}_{2}$ at room temperature for $10 \mathrm{~min}$, washed with $\mathrm{CaCl}_{2}$ and then incubated for $40 \mathrm{~min}$ with $2500 \mathrm{U} / \mathrm{mL}$ hyaluronidase (Sigma-Aldrich) in $0.1 \mathrm{mM} \mathrm{CaCl}_{2}$ at $37^{\circ} \mathrm{C}$. Non-specific background was blocked with PBS containing $1 \mathrm{mg} / \mathrm{mL}$ BSA, $10 \%$ FBS and $0.1 \%$ Triton (Applichem) for $30 \mathrm{~min}$. Sections were incubated overnight at $4^{\circ} \mathrm{C}$ with monoclonal mouse anti-collagen type II antibody (1:20; II-II6B3, Developmental Studies Hybridoma Bank, Ames, IA, USA) in blocking solution. After washing with $0.1 \mathrm{mM} \mathrm{CaCl}$, sections were incubated with a secondary biotinylated goat anti-mouse antibody (1:200; B0529, Sigma-Aldrich), and then with streptavidin-peroxidase polymer (1:200; S2438, Sigma-Aldrich) for $45 \mathrm{~min}$ at room temperature. Collagen type II was visualized by reaction with $0.075 \%$ solution of 3-amino-9-ethylcarbazole (AEC, Applichem) in $0.01 \%$ $\mathrm{H}_{2} \mathrm{O}_{2}$. Sections were mounted with $70 \%$ glycerol (Applichem) and examined by light microscopy.

Histological detection of GAG accumulation was carried out by alcian blue staining. Sections were stained overnight with $0.4 \%$ alcian blue, dissolved in $0.01 \% \mathrm{H}_{2} \mathrm{SO}_{4}$ (Applichem) and $0.5 \mathrm{M}$ guanidine hydrochloride (Fluka). Next, sections were washed for $30 \mathrm{~min}$ in $40 \%$ DMSO and $0.05 \mathrm{M} \mathrm{MgCl}_{2}$ (both from Applichem), mounted with $70 \%$ glycerol and examined by light microscopy.

\section{Statistics}

The Wilcoxon non-parametric test for dependent variables was used to compare gene expression, DNA quantification and GAG accumulation. Values are reported as mean \pm SD. Data analysis was performed with SPSS 14.0 for Windows (SPSS Inc., Chicago, IL, USA) and a significance value of $p<0.05$ was specified. 
A

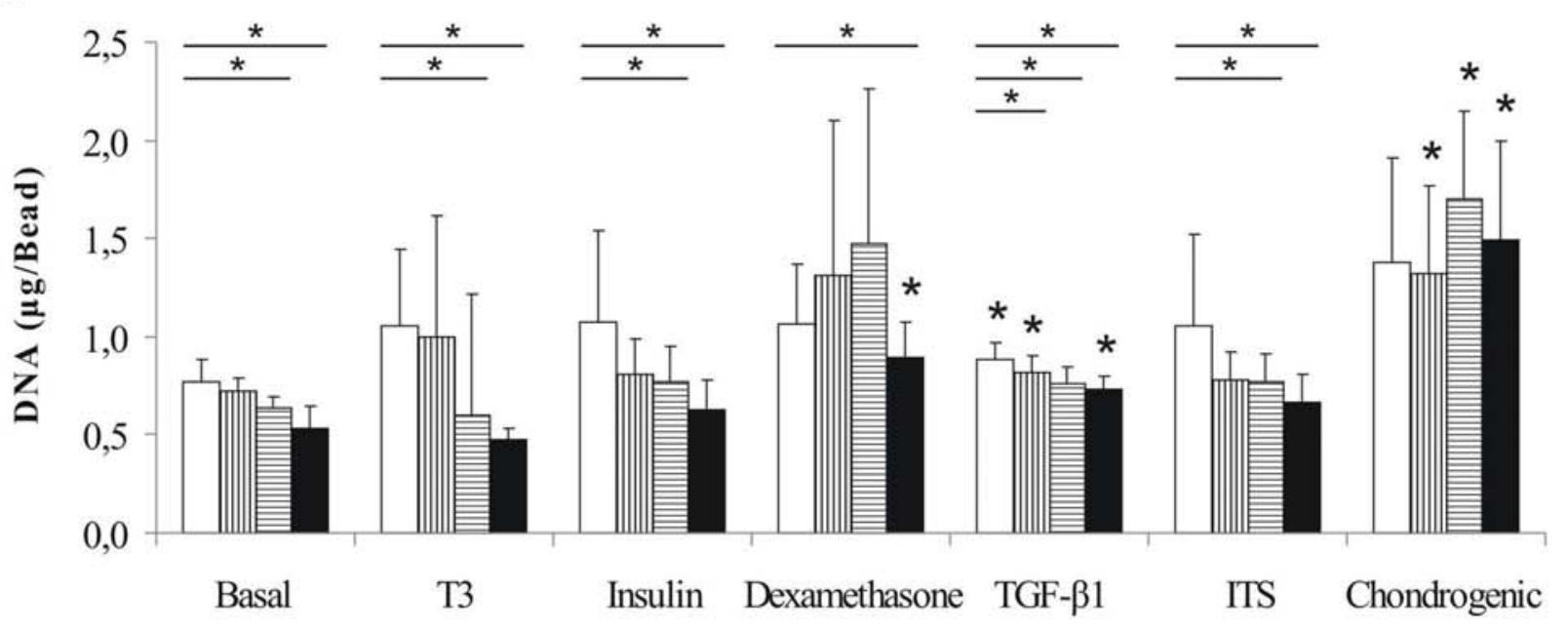

B

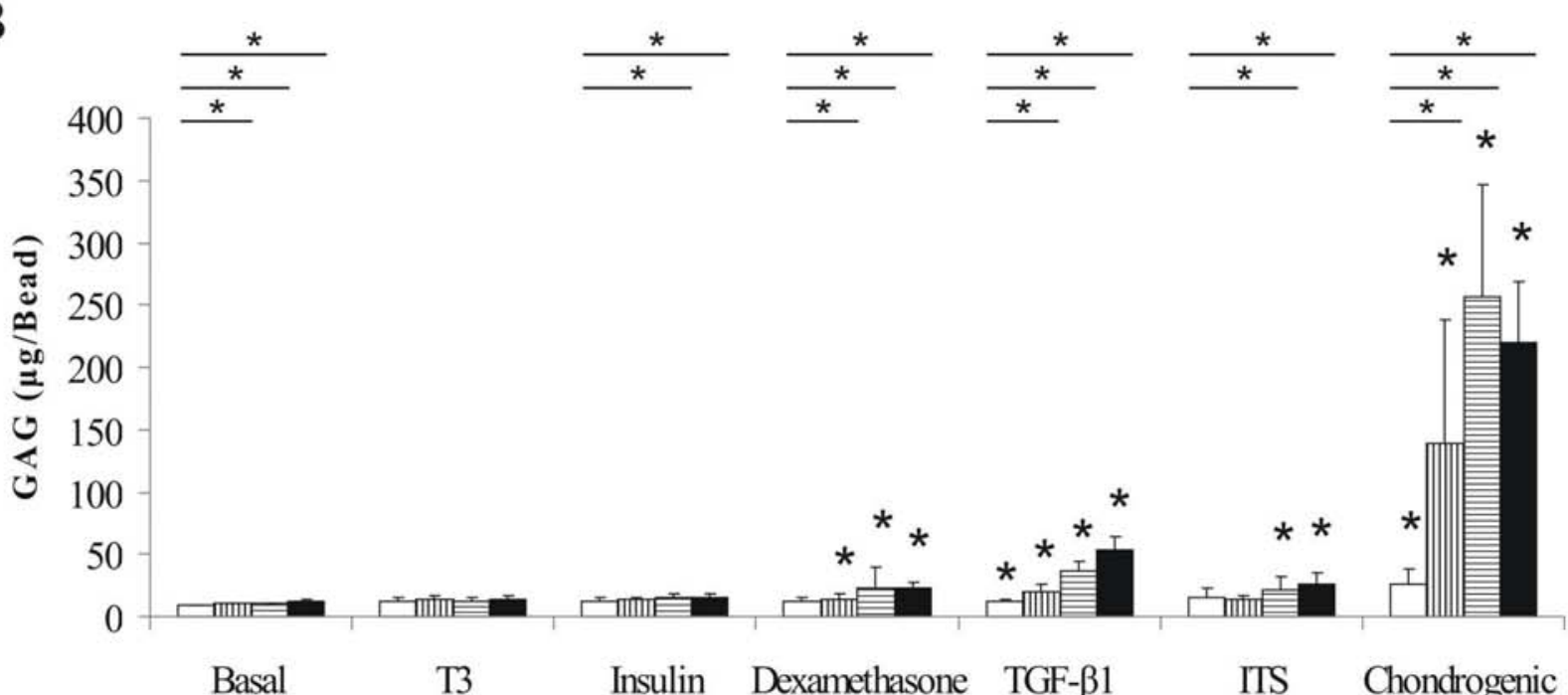

C

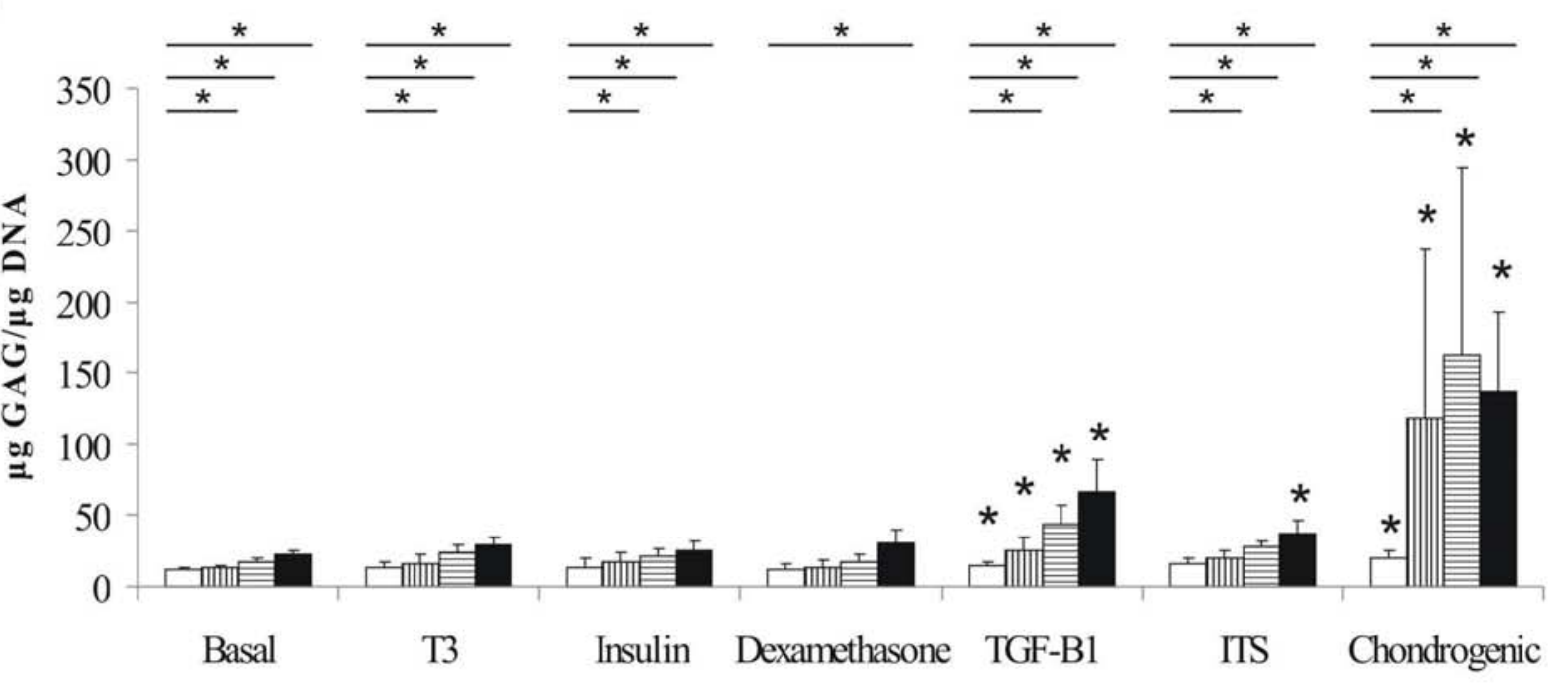

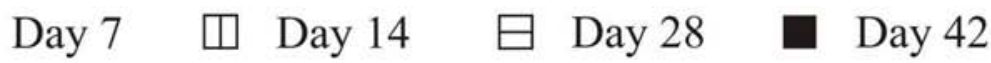

Fig. 1. DNA quantification of IVD cells in three-dimensional alginate bead cultures in T3, insulin, dexamethasone, TGF- $\beta 1$, ITS and chondrogenic media over 42 days (A) effect on GAG accumulation per bead (B) and normalized to DNA $(\mathbf{C})$ by IVD cells in the same samples. (Values represent the triplicate mean \pm standard deviation; $*=p<0.05$ compared to basal medium of the respective time point, * above bar $=p<0.05$ within the group [time course]). 
A

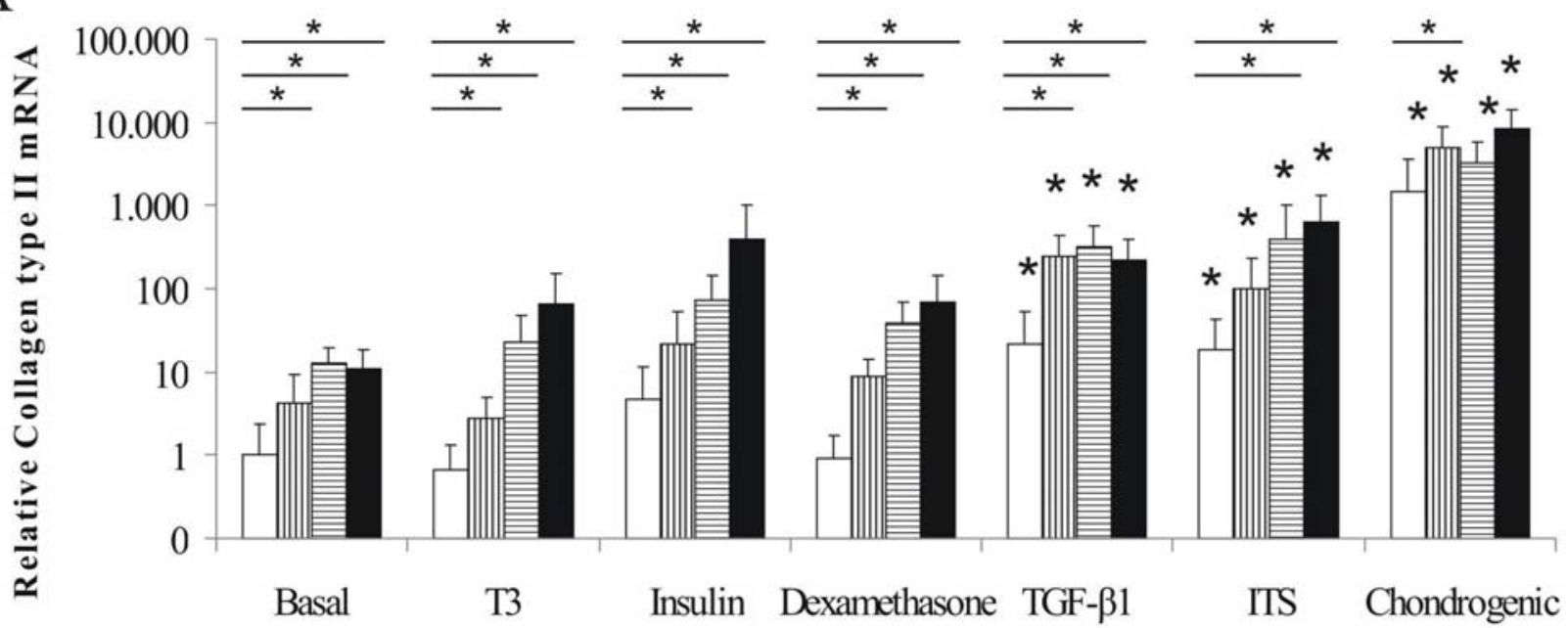

B

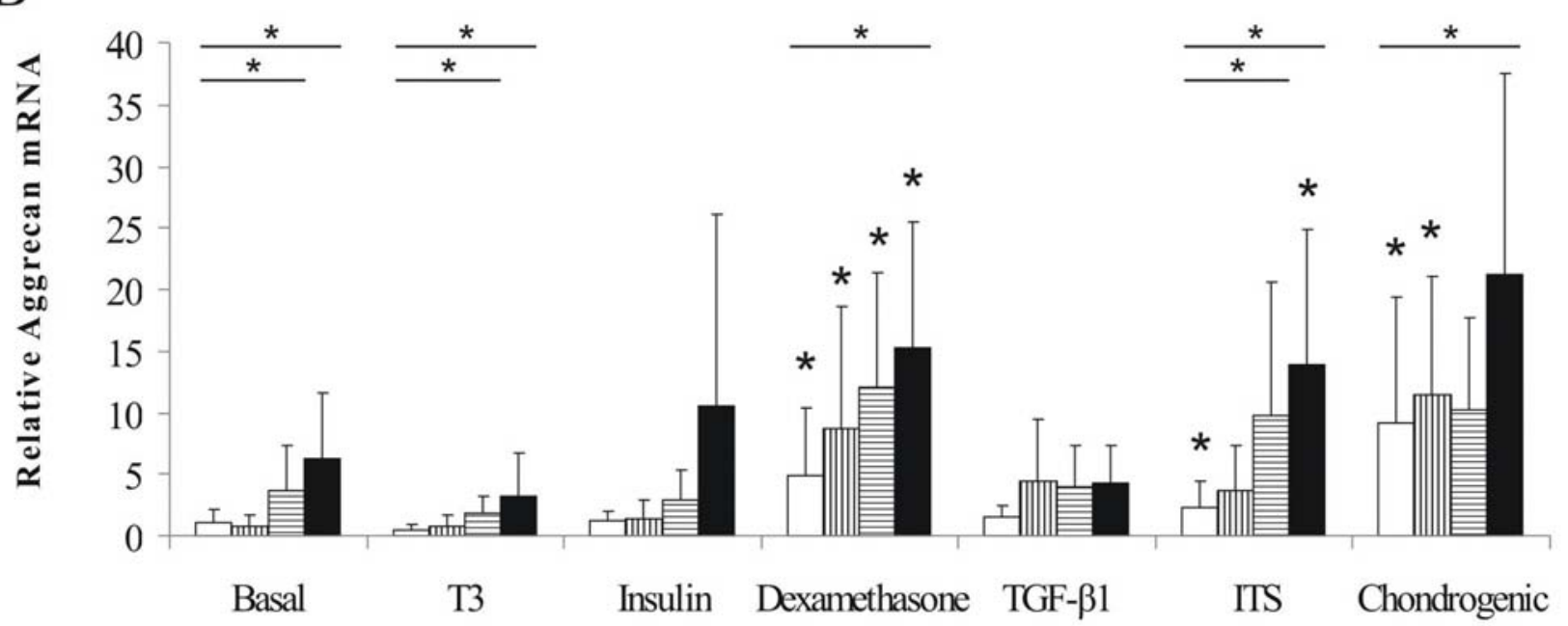

\section{Day $7 \square$ Day $14 \quad \boxminus$ Day $28 \square$ Day 42}

Fig. 2. Gene expression of collagen type II (A) and aggrecan (B) by IVD cells in alginate beads cultured in different media. Quantitative RT-PCR analysis (Relative expression normalized to GAPDH and to basal medium at day 7 , represented as a mean $\pm \mathrm{SD}, *=p<0.05$ compared to basal medium of the respective time point, $*$ above bar $=$ $p<0.05$ within the group [time course]).

\section{Results}

Effects of dexamethasone, insulin, and T3 on cell number Double stranded DNA content was measured for all samples in order to estimate cell number (Fig. 1A). At day 42 there was an overall trend of constant decrease (average $37 \% \pm 11 \%$, compared to day 7) of human disc cells survival - except in the chondrogenic medium, where DNA concentration from day 14 was stable and significantly higher compared to other media. This was also partially observed in the dexamethasone group, where an absolute - but non-significant - increase was observed until day 28 , followed by a drop by day 42 . However, compared to basal medium at day 42 , cells in the dexamethasone-treated group showed a significant increase of $75.3 \%(p<0.05)$ and approximately of $30 \%$ for the TGF- $\beta 1$-group $(p<0.05)$. Similar $30 \%$, however - non significant, increase was measured for the ITS-treated group.
Effects of dexamethasone, insulin, and T3 on GAG accumulation

Human disc cells showed a clear trend of time-dependent increase of GAG accumulation (Fig. 1B), except for cells grown in T3-supplemented medium (when GAG was normalized per bead). The overall accumulation of GAG by human cells, after 42 days of culture, showed a significant four-fold increase over the basal medium in the TGF- $\beta 1$-treated group $(p<0.05)$ and an approximately two-fold increase for the dexamethasone-treated group $(p<0.05)$, while there was no significant changes induced by insulin and T3. In particular, in the group treated with TGF- $\beta 1$, there was already a constant significant increase of up to $42 \%(p<0.05)$ in GAG concentration, compared to basal medium, after one week. In contrast, in the dexamethasone- and ITS-treated groups, a significant increase was observed only after 14 and 28 days, respectively. As a positive control, the group cultured in 
A
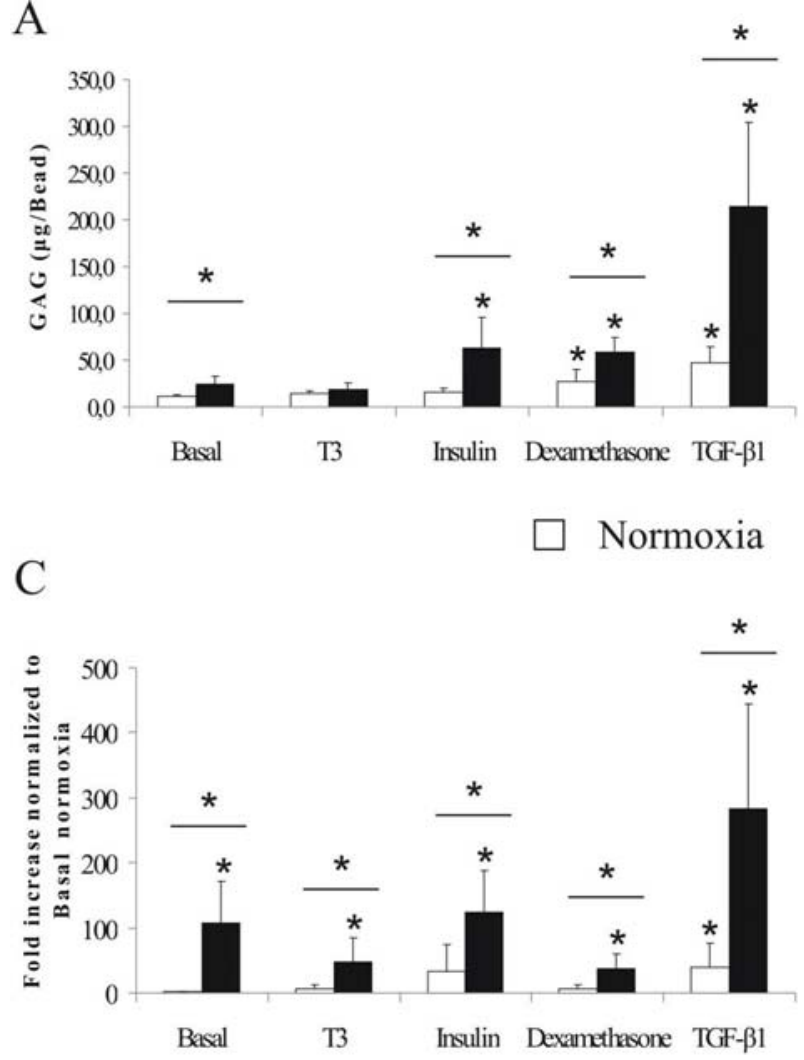

B

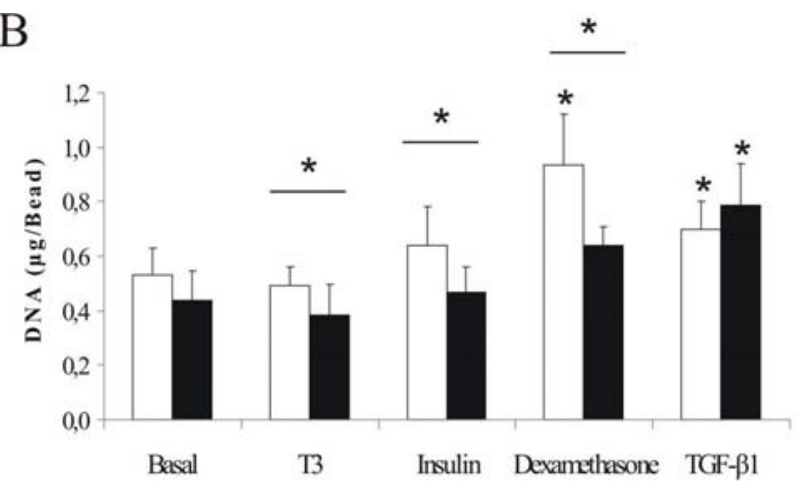

$\mathrm{D}$

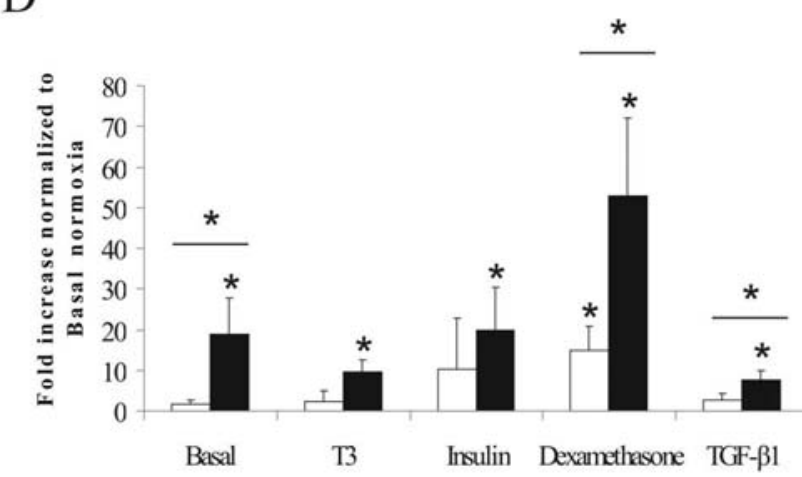

Fig. 3. Comparison between normoxic and hypoxic cultures of disc cells in three-dimensional alginate bead cultures. Comparison was performed analyzing: GAG accumulation (A), DNA amount (B), collagen type II (C) and aggrecan gene expression (D). Analyses were conducted after 42 days of culture. (Relative expression normalized to GAPDH and to basal medium under normoxic conditions, represented as a mean $\pm \mathrm{SD}, *=p<0.05$ compared to basal medium in normoxia, * above bar $=p<0.05$ within the group).

optimized chondrogenic medium accumulated a significantly greater amount of GAG compared to basal medium, showing an approximately seventeen-fold increase after 42 days $(p<0.05)$. However, if $\mathrm{GAG}$ accumulation was normalized to DNA, only TGF- $\beta 1$ and chondrogenic-treated groups were constantly stimulating IVD cells' production of GAG significantly during the whole course of the experiments (Fig. 1C). Compared to basal medium at day 42 , cells showed a significantly increased 7 fold GAG accumulation in the chondrogenic group $(p<0.05), 3$ fold increase in the TGF- $\beta 1$-group $(p<0.05)$ and approximately 2 fold increase in ITS-treated group $(p<0.05)$, while no significant effects were observed in the other media.

\section{Real-time quantitative PCR}

Quantitative PCR of collagen type II (Fig. 2A) and aggrecan (Fig. 2B) in human disc cells cultures, treated with the different media, were compared to the basal medium at different time points. Collagen type II expression increased with time in all media, but only in the TGF- $\beta 1$ , ITS- and chondrogenic- supplemented groups there was a significant increase $(p<0.05)$ compared to the basal medium. Interestingly, the TGF- $\beta 1$ supplementation showed a major increase of collagen type II expression in the first 14 days of culture, while ITS was more effective at day 28 and 42 . The greatest significant increase $(p<0.05)$ compared to the basal media (755 fold at day 42) was in the chondrogenic group.
Aggrecan gene expression also showed a timedependent increase in all groups, except in the TGF- $\beta 1$ treated group where, following 14 days, the number of RNA copies stabilized for the remainder of the experiment. Surprisingly, the dexamethasone group was the only one where gene expression of aggrecan was significantly upregulated at all time points $(p<0.05)$. Interestingly, the dexamethasone- and chondrogenic-treated groups had the highest ratio of aggrecan induction at day 14 (approximately 12-fold increase compared to basal medium) but at day 42, only dexamethasone- and ITStreated cells were significantly upregulating aggrecan expression $(p<0.05)$.

Comparison of effects of dexamethasone, insulin and T3 in normoxic and hypoxic cultures

Human disc cells cultured under hypoxic conditions (2\% $\mathrm{O}_{2}$ ) for 42 days showed a significant enhancement of GAG accumulation in all media $(p<0.05)$, except for the T3group (Fig. 3A). In the basal- and dexamethasone-group, there was a two-fold increase compared to normoxia. In the case of insulin-treated cells, the increase was fourfold and GAG accumulation in TGF- $\beta 1$-group under hypoxia increased by five-fold $(200 \mu \mathrm{g} / \mathrm{mL}$, thus identical to the optimized chondrogenic medium in normoxia). Cell viability under hypoxic conditions, represented by total DNA amount, showed a significant reduction in all the media, except in basal- and TGF- $\beta 1$-treated cells (Fig. 3B). In particular, DNA showed a reduction of almost $30 \%$ in 
A Basal T3 Insulin Dexamethasone TGF- $\beta 1$

Normoxia

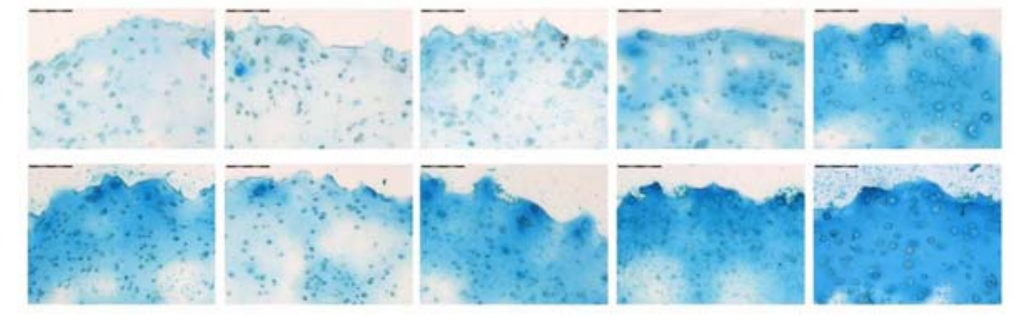

ITS

Hypoxia

Chondrogenic

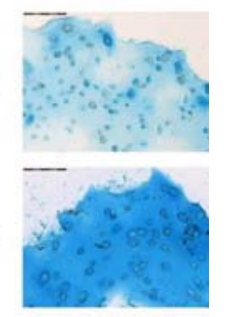

B

Basal $\mathrm{T} 3$ Insulin Dexamethasone TGF- $\beta 1$

Normoxia
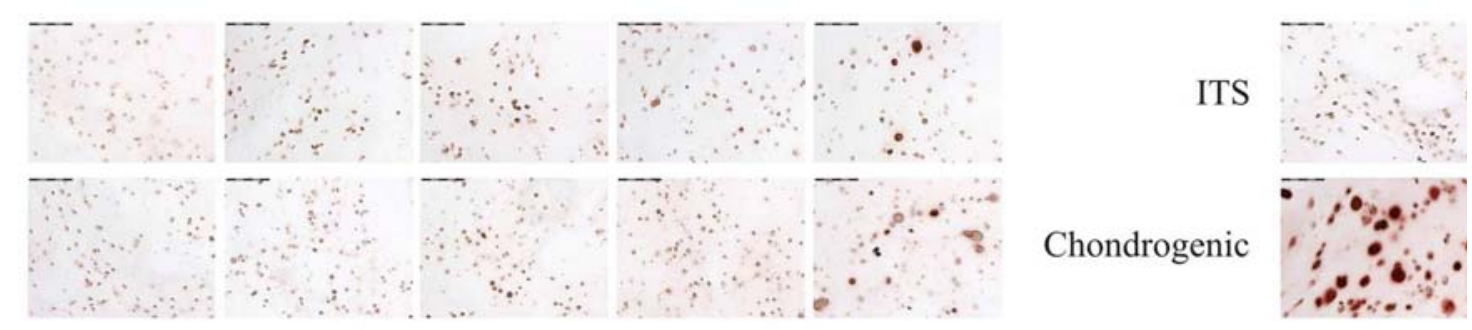

Fig. 4. Microphotographs of alginate beads sections stained with alcian blue after 42 days of culture (A). The deposition of proteoglycan-rich extracellular matrix is defined by increase in the blue staining. On the bottom panel, immunohistochemical analysis of collagen type II (B). Positive staining is indicated by the spotted red-colored extracellular matrix. Cellular morphology shows differences among the groups (All scale bars are $125 \mu \mathrm{m}$ ).

the insulin- and dexamethasone-treated groups $(p<0.05)$ and by $20 \%$ in the T3-treated groups $(p<0.05)$.

Collagen type II expression was significantly enhanced by hypoxia in all groups $(p<0.05)$ (Fig. 3C). Particularly impressive, the cells in the basal media group had an approximately 80 fold increase compared to the same group in normal oxygen conditions. Within the other groups, collagen type II expression went up on average seven fold. Aggrecan gene expression also increased under hypoxia, but only in basal-, dexamethasone and TGF- $\beta 1$ treated groups was the increase significant (Fig. 3D, $p<0.05)$. As in the case of collagen type II, cells cultured in basal medium had the highest relative increase within the group (eleven-fold compared to normoxic culture). Meanwhile cells in the other groups showed an average threefold increase.

\section{Histological and immunohistochemical staining}

The quantitative data for GAG accumulation was confirmed in all groups by histological staining of alginate bead sections with alcian blue at 42 days of culture (Fig. 4A). In normoxia, staining of dexamethasone-treated beads was higher compared to T3- and insulin-treated groups, but still lower than with TGF- $\beta 1$. Hypoxia was a major inducing factor for accumulation of GAG, to the extent that both TGF- $\beta 1$-treated and dexamethasone groups showed staining comparable to that of the fully optimized chondrogenic culture in normoxia. A very intensive blue staining, indicating strong GAG production was observed directly around the cells, especially in the case of the chondrogenic group.
The localization of collagen type II in bead sections was determined by immunostaining under normoxic and hypoxic conditions after 42 days in culture (Fig. 4B). As expected, collagen type II accumulation was highest in the chondrogenic group, and almost undetectable in other groups, except in the TGF- $\beta 1$-treated beads.

\section{Discussion}

This study had the practical purpose of testing readily available bioactive molecules, which are widely used in clinical practice, as a substitute to expensive, unapproved or proprietary growth factors. Three molecules were hypothesized to preserve or enhance cell survival and extracellular matrix synthesis of primary disc cells isolated from degenerated intervertebral tissue. IVD cells were isolated from mildly to moderately degenerated tissues (Thompson grades 2-3) and in one case from a highly degenerated tissue (Thompson grade 4). Irrespective of the grade of degeneration, all IVD cells responded to T3, insulin, dexamethasone, TGF- $\beta 1$ and ITS supplementation.

We advocate that GAG accumulation assay data in this particular case were normalized per bead and not to total DNA, as commonly done, for the following reasons: firstly, alginate beads had, initially, the same cell number (hence DNA content); secondly, we were interested in the total deposition of GAG in the extracellular matrix and normalization to DNA at different time points would bias the GAG amount to appear greater in groups where there is decreased DNA (control, T3, insulin), i.e., cell death. We can see that when GAG accumulation assay data were 
normalized to total DNA the sensitivity of the method is reduced when the supplementing factors are affecting the cell number.

As expected for fully differentiated disc cells, all groups, including those in the negative control (basal medium, no added growth factors) showed a trend of increased GAG synthesis with time. Cells treated with dexamethasone and TGF- $\beta 1$ produced more GAG per bead compared to the insulin, T3 and basal medium groups, after 14 days in culture. However, the effect of dexamethasone on GAG accumulation by IVD cells is lower and not significant when normalized to DNA, due to the large number of cells retained per bead. In the chondrogenic medium, the synergistic effect of TGF- $\beta 1$, dexamethasone and insulin (as part of ITS) provided a superior effect compared to the results obtained for the single molecules. Among the molecules tested, dexamethasone was the only one able positively to affect cell survival. Indeed, the only other medium that had a positive effect on cell survival was the chondrogenic medium (containing dexamethasone). Cell proliferation was affected neither by insulin nor by $\mathrm{T} 3$, rendering $\mathrm{T} 3$ as the least active of the tested molecules.

The ability of dexamethasone to enhance extracellular matrix synthesis was also tested both by analysis of aggrecan and collagen type II gene expression, and it proved to be the only molecule that significantly stimulated the expression of aggrecan during the whole experimental period. In contrast, the chondrogenic medium, which contains dexamethasone, had a significant effect on aggrecan production only in the first two weeks. Interestingly, TGF- $\beta 1$ alone did not affect aggrecan expression - and in the last week reduced the expression below that detected in basal medium. This result could explain why, in respect to aggrecan expression, chondrogenic medium was not performing as well as the dexamethasone-only medium. On the other hand, the major role of dexamethasone in aggrecan expression was not reflected by positive correlation with collagen type II gene expression. The absence of a proper collagen network, which can contain other extracellular matrix molecules, could be the main reason for the low accumulation of GAG, when measured by the alcian blue assay. In the case of collagen type II expression, both insulin and ITS played important roles. ITS supplementation stimulated COL2 significantly compared to basal medium and had a comparable effect to that of TGF- $\beta 1$ alone, while the effects of other molecules were not significantly different from basal medium. While, collagen type II expression was induced strongly by TGF- $\beta 1$ during the first two weeks of culture, insulin had a delayed action and was more effective in the final weeks. This might be because of insulin's similarity to insulin-like growth factor-I (IGF-I), and its ability to bind to the IGF-I receptor (Quarto et al., 1992; Kawaguchi et al., 2005). Even at lower concentrations, at which insulin does not bind to the IGF-I receptor, it can act as a proliferative and differentiating chondrogenic agent (Phornphutkul et al., 2006), thus stimulating collagen type II expression. It should be stressed, especially in the case of collagen type II expression, that the expression levels obtained by chondrogenic medium were much higher than the sum of using single molecules added to basal medium. This leads to the important conclusion that synergistic results can be obtained when growth factors are combined in a chondrogenic cocktail and demonstrates the complex needs of IVD cells for appropriate signaling. However, in the case when some of these growth factors were already synthesized to satisfactory levels in vivo, stimulatory action can be achieved only by adding the missing ones.

Hypoxia proved to improve proteoglycan accumulation significantly in all media, except in the T3 treated group, while cell viability was equal or even lower in hypoxia compared to normoxia. The general increase of GAG in the extracellular matrix was mirrored also by an increase in gene expression of collagen type II. Aggrecan gene expression was increased only in the basal and TGF- $\beta 1$ media, but the incubation in hypoxic conditions greatly increased proteoglycan accumulation in the TGF- $\beta 1$ group to values identical to those of chondrogenic medium in normoxia, thus "compensating" for the lack of dexamethasone and insulin. Also remarkably, hypoxia combined with insulin- and dexamethasone-supplemented media stimulated GAG accumulation to a greater level than TGF- $\beta 1$ in normoxic conditions.

Since the aim of this study was to evaluate whether readily available bioactive molecules could be used for stimulation and activation of isolated IVD cells and their further re-implantation in vivo, it is important to mention known limitations of the used molecules. Dexamethasone and T3 have been shown to induce hypertrophic differentiation in chondrocytes and endochordal ossification in culture (Quarto et al., 1992; Miura et al., 2002). Additionally, the use of $10 \%$ serum is not suitable for clinical application; however at lower serum concentrations a greatly increased cell death occurs after more than two weeks in cultures which are not supplemented with growth factors, therefore excluding the use of important controls. However, the ongoing efforts in the development of serum-free media (the topic of other studies) should solve this problem. As a conclusion, we could show that dexamethasone is a valuable, readily available molecule for maintaining cell survival and induction of proteoglycan synthesis in human disc cells, which has a strong synergistic effect together with TGF$\beta 1$ and ITS, resulting in a dramatic improvement of the GAG content. Valuable but somewhat unexpected results were also obtained in hypoxic culture, where insulin- and dexamethasone-treated cells produced a greater amount of proteoglycan than TGF- $\beta 1$-treated cells in normoxic culture, suggesting not only a possible application of these medically approved molecules for research but also in the hypoxic IVD environment in vivo. As a next step, these molecules will be also tested in an established ex-vivo, whole organ, disc degeneration model (Haschtmann et al., $2006 a, b)$ to investigate the effects of those molecules on a higher organizational level.

\section{Acknowledgements}

This study was supported in part by funding from KTI/ CTI (Switzerland) \#7081.2 LSPP-LS. AB and JS are 
supported by the Swiss Paraplegic Foundation. The authors declare no conflicting interests.

\section{References}

Adams MA., Roughley PJ (2006) What is intervertebral disc degeneration, and what causes it? Spine 31: 21512181 .

Antoniou J, Steffen T, Nelson F, Winterbottom N, Hollander AP, Poole RA, Aebi M, Alini M (1996) The human lumbar intervertebral disc: evidence for changes in the biosynthesis and denaturation of the extracellular matrix with growth, maturation, ageing, and degeneration. J Clin Invest 98: 996-1003.

Bjornsson S (1993) Simultaneous preparation and quantitation of proteoglycans by precipitation with alcian blue. Anal Biochem 210: 282-291.

Borenstein DG, O'Mara JW, Jr, Boden SD, Lauerman WC, Jacobson A, Platenberg C, Schellinger D, Wiesel SW (2001) The value of magnetic resonance imaging of the lumbar spine to predict low-back pain in asymptomatic subjects: a seven-year follow-up study. J.Bone Joint Surg Am 83-A: 1306-1311.

Chadderdon RC, Shimer AL, Gilbertson LG, Kang JD (2004) Advances in gene therapy for intervertebral disc degeneration. Spine J 4: 341S-347S.

Chujo T, An HS, Akeda K, Miyamoto K, Muehleman C, Attawia M, Andersson G, Masuda K (2006) Effects of growth differentiation factor-5 on the intervertebral discin vitro bovine study and in vivo rabbit disc degeneration model study. Spine 31: 2909-2917.

Derfoul A, Perkins GL, Hall DJ, Tuan RS (2006) Glucocorticoids promote chondrogenic differentiation of adult human mesenchymal stem cells by enhancing expression of cartilage extracellular matrix genes. Stem Cells 24: 1487-1495.

Dever TE (2002) Gene-specific regulation by general translation factors. Cell 108: 545-556.

Fei QM, Jiang XX, Chen TY, Li J, Murakami H, Tsai KJ, Hutton WC (2006) Changes with age and the effect of recombinant human BMP-2 on proteoglycan and collagen gene expression in rabbit annulus fibrosus cells. Acta Biochim Biophys Sin (Shanghai) 38: 773-778.

Grigoriadis AE, Aubin JE, Heersche JN (1989) Effects of dexamethasone and vitamin D3 on cartilage differentiation in a clonal chondrogenic cell population. Endocrinology 125: 2103-2110.

Gruber HE, Norton HJ, Leslie K, Hanley EN Jr (2001) Clinical and demographic prognostic indicators for human disc cell proliferation in vitro: pilot study. Spine 26: 2323 2327.

Hanken J, Summers CH (1988) Skull development during anuran metamorphosis: III. Role of thyroid hormone in chondrogenesis. J Exp Zool 246: 156-170.
Haschtmann D, Stoyanov JV, Ettinger L, Nolte LP, Ferguson SJ (2006) Establishment of a novel intervertebral disc/endplate culture model: analysis of an ex vivo in vitro whole-organ rabbit culture system. Spine 31: 2918-2925.

Haschtmann D, Stoyanov JV, Ferguson SJ (2006) Influence of diurnal hyperosmotic loading on the metabolism and matrix gene expression of a whole-organ intervertebral disc model. J Orthop Res 24: 1957-1966.

Johnstone B, Hering TM, Caplan AI, Goldberg VM, Yoo JU (1998) In vitro chondrogenesis of bone marrowderived mesenchymal progenitor cells. Exp Cell Res 238: 265-272.

Kawaguchi J, Mee PJ, Smith AG (2005) Osteogenic and chondrogenic differentiation of embryonic stem cells in response to specific growth factors. Bone 36: 758-769.

Lee CK, Langrana NA (2004) A review of spinal fusion for degenerative disc disease: need for alternative treatment approach of disc arthroplasty? Spine J 4: 173S-176S.

Miura M, Tanaka K, Komatsu Y, Suda M, Yasoda A, Sakuma Y, Ozasa A, Nakao K (2002) Thyroid hormones promote chondrocyte differentiation in mouse ATDC5 cells and stimulate endochondral ossification in fetal mouse tibias through iodothyronine deiodinases in the growth plate. J Bone Miner Res 17: 443-454.

Na K, Park JH, Kim SW, Sun BK, Woo DG, Chung HM, Park KH (2006) Delivery of dexamethasone, ascorbate, and growth factor (TGF beta-3) in thermoreversible hydrogel constructs embedded with rabbit chondrocytes. Biomaterials 27: 5951-5957.

Phornphutkul C, Wu KY, Gruppuso PA (2006) The role of insulin in chondrogenesis. Mol.Cell Endocrinol. 249: 107-115.

Quarto R, Campanile G, Cancedda R, Dozin B (1992) Thyroid hormone, insulin, and glucocorticoids are sufficient to support chondrocyte differentiation to hypertrophy: a serum-free analysis. J Cell Biol 119: 989995.

Quarto R, Campanile G, Cancedda R, Dozin B (1997) Modulation of commitment, proliferation, and differentiation of chondrogenic cells in defined culture medium. Endocrinology 138: 4966-4976.

Tsai TT, Guttapalli A, Oguz E, Chen LH, Vaccaro AR, Albert TJ, Shapiro IM, Risbud MV (2007) Fibroblast growth factor-2 maintains the differentiation potential of nucleus pulposus cells in vitro: implications for cell-based transplantation therapy. Spine 32: 495-502.

Walsh AJ, Bradford DS, Lotz JC (2004) In vivo growth factor treatment of degenerated intervertebral discs. Spine 29: $156-163$.

Editor's Note: All questions/comments from the reviewers were answered by text changes in the manuscript. Hence, there is no "Discussion with Reviewers" section. 